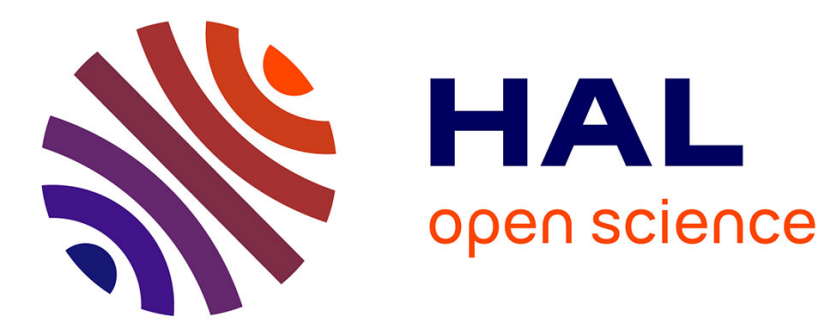

\title{
What about the Backbone Conformation in Nematic and Smectic C Phases of a "Side-on" Fixed LCP? A SANS Study
}

\author{
S. Lecommandoux, Laurence Noirez, M. Achard, F. Hardouin
}

\section{To cite this version:}

S. Lecommandoux, Laurence Noirez, M. Achard, F. Hardouin. What about the Backbone Conformation in Nematic and Smectic C Phases of a "Side-on" Fixed LCP? A SANS Study. Journal de Physique II, 1997, 7 (10), pp.1417-1424. 10.1051/jp2:1997194 ～jpa-00248524

HAL Id: jpa-00248524

https://hal.science/jpa-00248524

Submitted on 1 Jan 1997

HAL is a multi-disciplinary open access archive for the deposit and dissemination of scientific research documents, whether they are published or not. The documents may come from teaching and research institutions in France or abroad, or from public or private research centers.
L'archive ouverte pluridisciplinaire HAL, est destinée au dépôt et à la diffusion de documents scientifiques de niveau recherche, publiés ou non, émanant des établissements d'enseignement et de recherche français ou étrangers, des laboratoires publics ou privés. 


\title{
What about the Backbone Conformation in Nematic and Smectic C Phases of a "Side-on" Fixed LCP? A SANS Study
}

\author{
S. Lecommandoux $\left({ }^{1}\right)$, L. Noirez $\left({ }^{2}\right)$, M.F. Achard $\left({ }^{1}\right)$ and F. Hardouin $\left({ }^{1, *}\right)$ \\ $\left({ }^{1}\right)$ Centre de Recherche Paul Pascal, Université Bordeaux I, avenue A. Schweitzer, \\ 33600 Pessac, France \\ $\left({ }^{2}\right)$ Laboratoire Léon Brillouin, Centre d'Études de Saclay $\left({ }^{* *}\right), 91191$ Gif sur Yvette, France
}

(Received 13 December 1996, received in final form 29 May 1997, accepted 11 June 1997)

PACS.61.30.-v - Liquid crystals
PACS.62.20.-x - Mechanical properties of solids
PACS.66.20.+d - Viscosity of liquids: diffusive momentum transport

\begin{abstract}
A polymorphism nematic - smectic $\mathrm{C}$ has been revealed for the first time in "side-on" fixed liquid crystalline polymers. By means of neutron investigations, structural and conformational results have been reported in both mesophases. An inversion of the backbone conformation is observed from the nematic phase to the smectic $\mathrm{C}$ phase. This new feature is compared to the well known situation of the $\mathrm{N}-\mathrm{S}_{\mathrm{A}}$ transition for "side-end" fixed liquid crystal polymers.
\end{abstract}

Résumé. - Un polymorphisme de type nématique - smectique $\mathrm{C}$ a été pour la première fois révélé dans les polymères cristaux liquides en "haltère". Des résultats structuraux et conformationnels obtenus par diffusion cohérente de neutrons sont présentés pour les deux mésophases. Une inversion de la conformation de la chaîne polymère est observée de la phase nématique à la phase smectique $\mathrm{C}$. Ce comportement original est comparé au cas de la transition $\mathrm{N}-\mathrm{S}_{\mathrm{A}}$ pour des polymères cristaux liquides en "peigne".

\section{Introduction}

The conjunction of structural and conformational informations are essential to give a description and an understanding of the relationships between the liquid crystal ordering and backbone entropy. Many informations can be obtained via Small Angle Neutron Scattering [1-12] and by X-ray diffraction $[13,14]$. It has been clearly shown that the chain of Liquid Crystal Polymers (LCP) become anisotropic in the different mesophases. In particular, most "side-end" fixed LCPs present an oblate backbone conformation in the smectic A phase [15], corresponding to a confinement of the chains between the mesogenic layers [9-12]. In contrast, "side-on" fixed LCPs generally exhibit the nematic phase [16-26]. Nevertheless, some authors have recently shown the existence of smectic phases for these last ones [27-31]. Different SANS studies in the nematic phase concerning the "side-on" fixed polymers have also revealed an anisotropic

$\left(^{*}\right)$ Author for correspondence (e-mail: f.hardouin@presidence-bx1.U-bordeaux.fr)

$\left({ }^{* *}\right)$ CEA - CNRS

(c) Tes Éditions de Physique 1997 
structure at the scale of the chain: the backbone is strongly stretched in the direction of its mesogens [1-8]. During these last years, we have studied the influence of the chemical architecture on this prolate shape of the chain. In particular, we have shown that the anisotropy of the backbone is reduced by increasing the spacer length $[4,7]$ or the aliphatic extremity length [7], by decreasing the ratio of mesogenic groups onto the same chain $[3,6]$ and also by playing on the nature of attachment of the mesogenic groups onto the polymer backbone for copolymer systems [32].

With the aim of a better understanding of the coupling "mesophase - backbone conformation" in LCPs, we report here the study by SANS of a "side-on" LCP which exhibits nematic and smectic C phases. This polymer, whose name is $\mathrm{P}_{10,6,6} 55 \%$ is termed "diluted". because only $55 \%$ of the lateral groups are liquid crystalline moieties. It corresponds to the following formula:

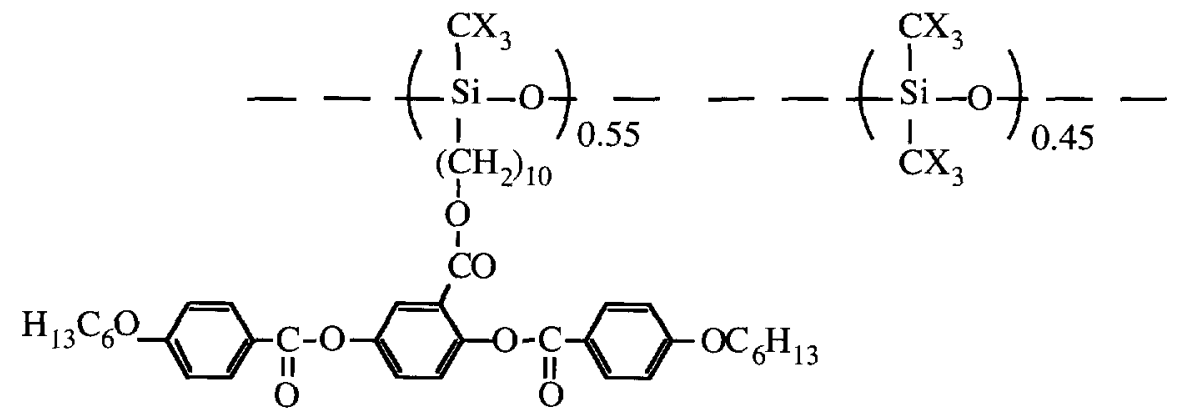

The number average molecular weight of each compound ( $\mathrm{X}=\mathrm{H}$ or $\mathrm{D}$ ) has been determined by gel permeation chromatography using a self made polysiloxane standardization. This last one has been realized in the laboratory with tonometry measurements of polysiloxane standards. It is thus possible to measure the absolute values of the average molecular weight in number $M_{\mathrm{n}}$ and the polymolecularity I: they were found similar for the hydrogenated and partially deuterated polymers $\left(M_{\mathrm{n}}=25000\right.$ and $\left.\mathrm{I} \approx 2.2\right)$. This polymer has been extensively characterized from a thermodynamical and structural points of view [33]. The results are summarized in Table I.

Table I. - Transition temperatures $\left({ }^{\circ} \mathrm{C}\right)$, g: glassy state, Sc: smectic $C$ phase, $N$ : nematic phase, I: isotropıc phase, $\Delta S_{I N}$ : entropy change at the IN transition (joule / Kelvin / unity of monomer), $\triangle S_{N S c}$ : entropy change at the NSc transition (joule / Kelvin / unity of monomer), Structural parameter ( $X$-ray diffraction), q: scattering vector $\left(\AA^{-1}\right), \theta$ : tilt angle $\left({ }^{\circ}\right)$, d: periodicity of the smectuc layers $(\AA)$.

\begin{tabular}{|c|c|c|c|c|c|c|c|c|c|c|}
\hline & \multicolumn{5}{|c|}{ Transition temperatures $\left({ }^{\circ} \mathrm{C}\right)$} & \multirow{2}{*}{$\begin{array}{c}\Delta S_{\mathrm{IN}} \\
\left(\mathrm{J} \mathrm{K}^{-1} \mathrm{um}^{-1}\right)\end{array}$} & \multirow{2}{*}{$\begin{array}{c}\Delta S_{\mathrm{NSc}} \\
\left(\mathrm{J} \mathrm{K}^{-1} \mathrm{um}^{-1}\right)\end{array}$} & \multirow{2}{*}{$\begin{array}{c}q \\
\left(\AA^{-1}\right)\end{array}$} & \multirow{2}{*}{$\begin{array}{c}\theta \\
(0)\end{array}$} & \multirow{2}{*}{$\begin{array}{c}d \\
(\AA)\end{array}$} \\
\hline & $\mathrm{g}$ & $\mathrm{Sc}$ & . & $\mathrm{N}$ & . I & & & & & \\
\hline $\mathrm{P}_{10,6,6} 55 \% \mathrm{H}$ & 14 & & 49 & & 76 & 0.86 & 2.9 & 0.21 & 44 & 29.9 \\
\hline $\mathrm{P}_{10,6,6} 55 \% \mathrm{D}$ & 14 & & 49 & & 71 & 0.83 & 3.1 & 0.21 & 44 & 29.9 \\
\hline Mixture H, D & 14 & & 49 & & 73 & 0.80 & 2.9 & - & - & - \\
\hline
\end{tabular}

The experimental procedure and the data process is described in the next section. The third section is devoted to the measurements of the polymer backbone dimensions respectively parallel and perpendicular to the direction of the mesogens (via SANS), and of the local mesogen organization (via Neutron Diffraction). The results will be discussed in the last part. 


\section{Experimental Device}

The SANS experiments have been performed according to the usual method [34] with a mixture containing, in equal parts, the hydrogenated and the deuterated polysiloxane. The mixture is placed in a quartz disc-like cell (thickness $1 \mathrm{~mm}$, diameter $15 \mathrm{~mm}$ ) and set in an oven (temperature stability of $\pm 0.05{ }^{\circ} \mathrm{C}$ ), itself put in the trajectory of the neutron beam. The orientation of the mesogens is obtained in situ by slowly cooling the sample from the isotropic phase, in a magnetic field of 1.4 tesla oriented perpendicular to the incident neutron beam. The neutrons scattered by the sample are collected on an XY sensitive multidetector PAXY (Orphée Reactor, CEN Saclay). The PAXY instrument allows the simultaneous observation of the small angle scattering signal associated to the backbone form factor and of the first smectic reflection (or any local order) under the same experimental conditions. This is obtained in our experiments by switching the initial wavelength $\lambda=10 \AA$ and sample-multidetector distance $d=2 \mathrm{~m}$ down to $\lambda=5 \AA$ and $d=1 \mathrm{~m}$.

2.1. ND Conditions. - The experimental conditions adopted ( $\lambda=5 \AA$ and $d=1 \mathrm{~m})$ lead to a scattering vector range $0.03 \AA^{-1}<q<0.3 \AA^{-1}$ Such conditions allow to observe the 001 smectic reflections on the PAXY multidetector. So we can observe in situ the evolution of the local order of the $\mathrm{P}_{10,6,6} 55 \%$ and, in particular at the approach of the nematic to smectic $\mathrm{C}$ transition.

2.2. SANS Conditions. - The SANS obtained with $\lambda=10 \AA$ and $d=2 \mathrm{~m}$ corresponds to a scattering vector $q=4 \pi \theta / \lambda$ (where $2 \theta$ is the scattering angle) included between $7 \times 10^{-3} \AA^{-1}<q<7 \times 10^{-2} \AA^{-1}$ A linear dependence of the inverse of the scattered intensity $I^{-1}(q)$ versus $q^{2}$ is observed over the most of this $q$ range. We applied in this range an extension of the Guinier approximation which takes into account the difference in molecular weights [35]. This scattering law assumes that no specific interaction occurs between labeled and unlabeled parts. It is corroborated with the fact that the intensity at the origin keeps constant value within $5 \%[36]$.

As both polymers $(\mathrm{H}$ and $\mathrm{D})$ have the same molecular weights, we can directly apply the Guinier approximation and write:

$$
\begin{aligned}
& I^{-1}\left(q_{\|}\right)=I^{-1}(0)\left(1+q_{\|}^{2} R_{\|\|}^{2}\right) \\
& I^{-1}\left(q_{\perp}\right)=I^{-1}(0)\left(1+q_{\perp}^{2} R_{\perp}^{2}\right)
\end{aligned}
$$

where $q_{\mathrm{i}}(\mathrm{i}=\|$ or $\perp$ ) denotes the component of the scattered vector along the direction $\mathrm{i}$, and $R_{\mathrm{i}}$ represents the quadratic size of the labeled polymer in the direction $\mathrm{i}$. Thus, the backbone dimensions $R_{\|}$and $R_{\perp}$ are deduced from these equations. After classical corrections [34], the dependence of these dimensions versus temperature could be reported with an error estimated to be less than $5 \%$.

\section{Experimental Results}

3.1. Neutron Diffraction Study. - Figure 1 shows the neutron diffraction patterns from $\mathrm{P}_{10,6,6} 55 \%$ in the nematic and smectic $C$ mesophases. In the low temperature nematic phase (Fig. 1a), four diffuse spots are observed located at $q=0.21 \AA^{-1}$ (which corresponds to a layer distance of $d=2 \pi / q=29.9 \AA$ ) with a tilt angle of $\theta=47^{\circ}$. They correspond to the tilted cybotactic groups usually observed in nematic LCPs above a $\mathrm{N}-\mathrm{S}_{\mathrm{C}}$ transition $[29,37-40]$. As expected, the intensity of these spots increases with decreasing temperature. At the nematic to smectic $\mathrm{C}$ transition (Fig. 1b), the diffuse spots are condensed in a set of Bragg reflections 


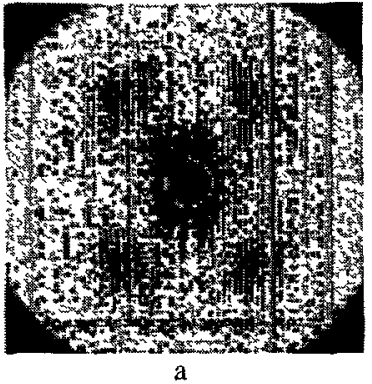

a

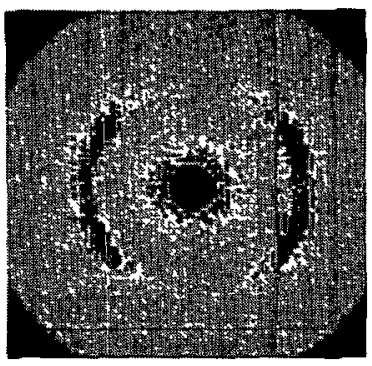

c

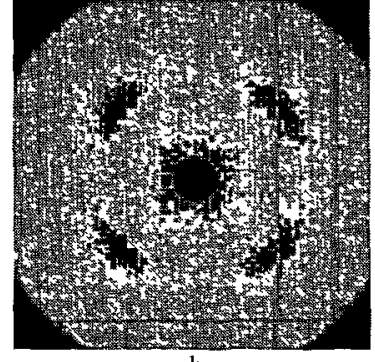

b

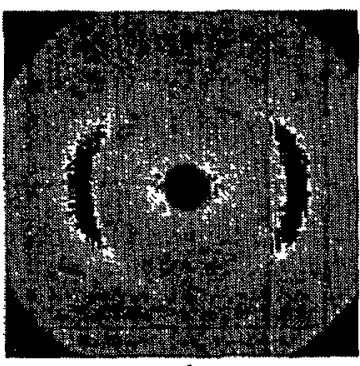

d

Fig. 1. - Neutron diffraction patterns of the H/D mixture corresponding to the $\mathrm{P}_{10,6,6} 55 \%$ under magnetic field. The direction of the magnetic field is horizontal. Kinetics of layer orientation: a) $T=52{ }^{\circ} \mathrm{C}$ in nematic phase 10 minutes exposure. b) $T=47^{\circ} \mathrm{C}$ in high smectic $\mathrm{C}$ phase, 5 minutes exposure. c) $T=47^{\circ} \mathrm{C}$ in high smectic $\mathrm{C}$ phase after waiting 30 minutes at this temperature, 5 minutes exposure. d) $T=42^{\circ} \mathrm{C}$ in smectic $\mathrm{C}$ phase 5 minutes exposure.

( $q=0.21 \AA^{-1}, \theta=44^{\circ}$ ). We observe the same characteristic features using X-ray diffraction. A more surprising result is shown in Figure 1c where the tilt angle of the layers decreases in the $\mathrm{S}_{\mathrm{C}}$ phase while the sample is kept at a constant temperature under the magnetic field $\left(q=0.21 \AA^{-1}, \theta=22^{\circ}\right.$ ). This dynamic reorganization is confirmed in Figure 1d where we have only two crescents with an angular extension. Finally, at the equilibrium, the normal to the smectic layers tends to be uniformly oriented whereas the mesogens are azymutally tilted in the layers. This effect is independent of the magnetic field since we have carried out an experiment with an oriented nematic sample: the same process of reorientation was observed at the nematic to smectic $\mathrm{C}$ transition without external magnetic field. This is probably connected to the anchoring of the sample and to the geometry of its confinement.

Once, the layer reorientation process achieved, we start SANS measurements in order to determine $R_{\|}$and $R_{\perp}$ associated to the backbone dimensions in the parallel and perpendicular directions to the normal of the layers. The fact that the layers are oriented is very important since the values of $R_{\|}$and $R_{\perp}$ have a physical signification: prolate or oblate conformation can be determined with the ratio $R_{\|} / R_{\perp}$ and compared to the anisotropy of other systems.

3.2. The SANS STUdY. - Figure 2 displays the distribution of the scattered intensity in the XY plane of the multidetector PAXY in each mesophase. In the isotropic phase (Fig. 2a), as expected no anisotropy can be detected in the intensity distribution. In the nematic phase, the shape of the scattering (Fig. 2b) indicates a polymer backbone tendency to adopt a weak prolate shape $\left(R_{\|} / R_{\perp}=1.2\right)$. Figure 3 displays the evolution of the polymer dimensions $R_{\|}$ 


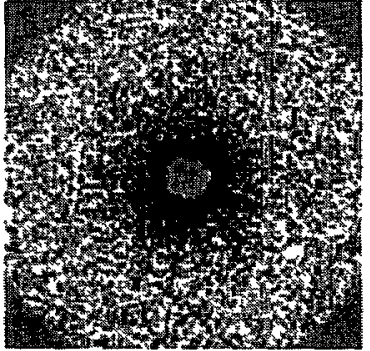

a

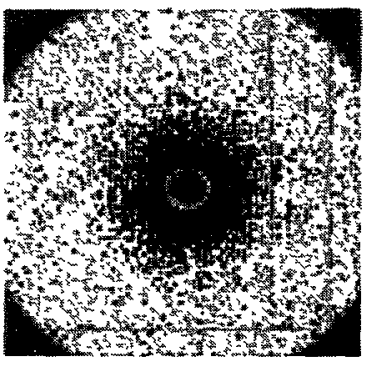

C
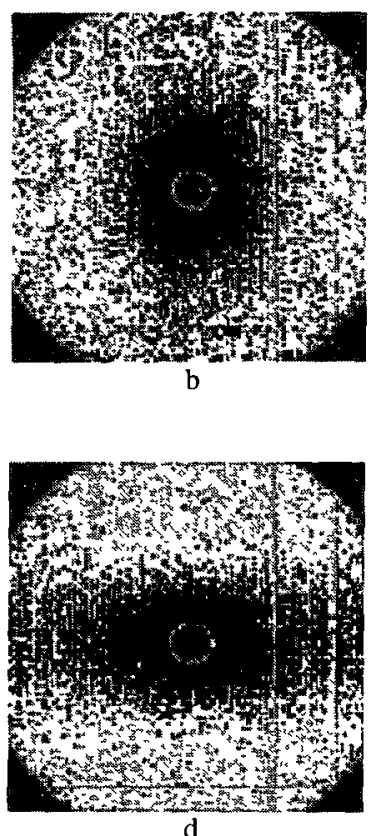

Fig. 2. - Signal measured on the H/D sample at small angle associated to the backbone form factor. Each cross represents a cell of the multidetector PAXY $\left(128 \times 128\right.$ cells of $\left.0.5 \mathrm{~mm}^{2}\right)$. The white disk in the center corresponds to the beam trap. The direction of the magnetic field is horizontal. a) The isotropic phase $\left(T=77^{\circ} \mathrm{C}\right)$ where the backbone adopts an isotropic conformation. b) The nematic phase $\left(T=52{ }^{\circ} \mathrm{C}\right)$ where the backbone conformation becomes weakly prolate. c) The nematic to smectic $\mathrm{C}$ transition $\left(T=49^{\circ} \mathrm{C}\right)$ where the backbone conformation adopts an intermediate isotropic conformation. d) The smectic $\mathrm{C}$ phase $\left(T=42{ }^{\circ} \mathrm{C}\right)$ where the backbone conformation is clearly oblate.

and $R_{\perp}$ as a function of temperature. It reveals a decrease of the dimension $R_{\|}$just above the nematic to smectic $\mathrm{C}$ transition, while $R_{\perp}$ remains a constant value (about $23 \AA$ ). At the transition temperature $\left(T=49^{\circ} \mathrm{C}\right.$ ), the conformation recovers an isotropic shape (Fig. 2c). In the smectic $\mathrm{C}$ phase, we simultaneously observe an increase of the $R_{\perp}$ value and a decrease of $R_{\|}$, resulting in an important oblate shape (Fig. 2d). Figure 3 indicates that the saturated values of the polymer dimensions in the $S_{C}$ are reached not too far from the nematic to smectic $\mathrm{C}$ transition (about $5^{\circ} \mathrm{C}$ ). It corresponds to the formation of an oblate shape of the backbone with respect to the magnetic field direction $\left(R_{\|} / R_{\perp}=0.5\right)$. The same result (backbone inversion) is obtained by heating the sample again in the nematic phase and then cooling with or without a magnetic field.

\section{Discussion and Conclusion}

The main result of this study is the reversible change of backbone conformation cooling from the nematic phase to the smectic $\mathrm{C}$ phase. The inherent questions of such a phenomenon concern the origins and the mechanism of the change of backbone conformation whatever the orientation process of the sample.

In the nematic phase, a weak prolate anisotropy is observed $\left(R_{\|} / R_{\perp}=1.2\right)$ due to the following reasons: a large spacer which decouples the mesogens from the backbone and a weak 


\section{$\mathbf{R}(\AA)$}

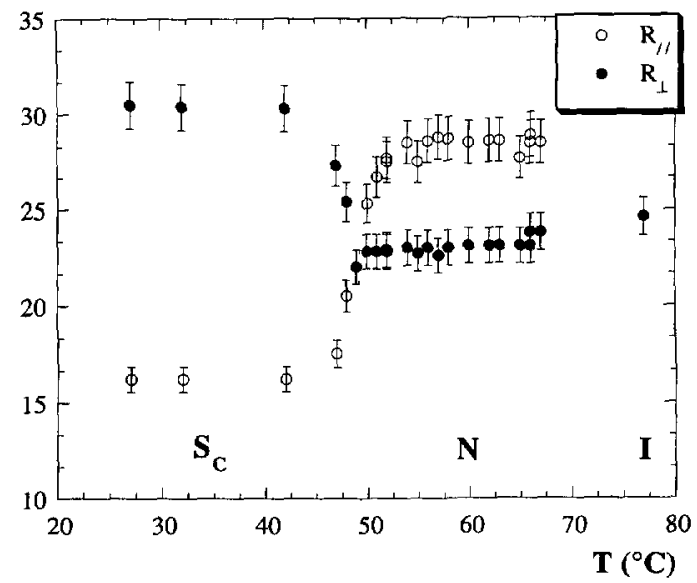

Fig. 3. - Values of the polymer backbone dimensions respectively parallel and perpendicular to the magnetic field direction $R_{\|}$and $R_{\perp}$ as a function of the temperature.

proportion of mesogens (55\%) which dilutes the mesomorphic properties [1-8]. This weak anisotropy is the result of a competition between the disorder due to the backbone entropy and the interaction energy between the "side-on" mesogens which induces a $\mathrm{N}_{\text {III }}$ type phase [32,41]. Further, this behaviour is qualitatively different from the weak oblate behaviour observed for "side-end" fixed LCP [9-12] in the nematic phase above a smectic A phase. Actually, in the latter cases the backbone presents a weak oblate shape in the nematic phase due to uniform orientation of the layers of the smectic A fluctuations near the $\mathrm{N}-\mathrm{S}_{\mathrm{A}}$ phase transition. In our system the layers of smectic $\mathrm{C}$ pretransitional effects are tilted and not uniformly oriented in the nematic phase. The corresponding prolate anisotropy decreases close to the $\mathrm{N}-\mathrm{S}_{\mathrm{C}}$ transition leading to an apparent isotropic shape at the transition temperature (Fig. $3 . T=49^{\circ} \mathrm{C}$ ). Below this transition an inversion of the backbone anisotropy occurs: the chains hence undergo the uniform orientation of the layers obtained here in the $S_{C}$ phase and consequently we detect a confinement effect. Saturated values of $R_{\|}$and $R_{\perp}$ are yet reached cooling down from a few degrees. The resulting oblate anisotropy is strong $\left(R_{\|} / R_{\perp}=0.5\right)$. In this situation, the energy corresponding to the chain entropy could be negligible compared to the energy of the smectic order. In fact, we have shown that the nematic to smectic entropy change $\Delta S_{\mathrm{NSc}}$ can be stronger in "diluted side-on" systems than in "side-end" homopolymers [33]. In order to illustrate the evidences structures, the Figure 4 represents a schematic view of the mesoscopic organization in the mesophases.

Moreover. we can note that an inversion of the backbone conformation has already been observed for a "side-end" fixed LCP at the smectic A - nematic reentrant phase transition [42]. By comparison with the high temperature nematic and smectic $A$ phases in which the backbone adopts an oblate shape, there is an inversion of the anisotropy in the reentrant nematic phase. This inversion of conformation in the high and low nematic phases seems connected to the presence or not of smectic A fluctuations.

It has been shown in nematic - smectic A system of "side-end" fixed LCP that the backbone confinement depends on the SA order parameter [10] and on the type of the smectic A structure $\left(S_{A 1}, S_{A d}\right)$. Similar question can be raised for the nematic - smectic C system of "side-on" fixed LCP described here. In addition, new investigations are in progress to test the specific 


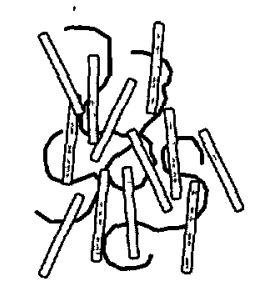

Isotropıc state

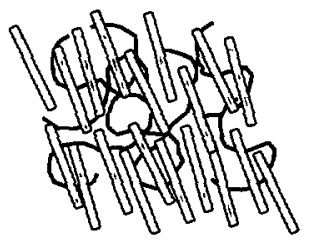

nematic- smectıc $\mathrm{C}$ transition

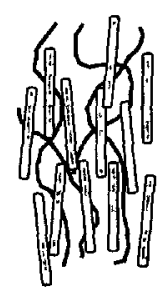

nematic phase

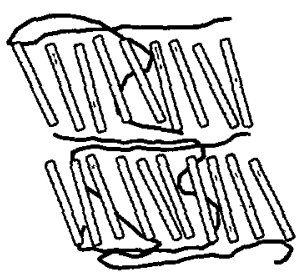

smectıc C phase

Fig. 4. - Schematic representation of the global organization from X-ray and DNPA measurements. The backbone conformation is isotropic in the isotropic state and becomes weakly prolate in the nematic phase. At the $\mathrm{N}-\mathrm{S}_{\mathrm{C}}$ transition the backbone becomes isotropic and strongly oblate in the $\mathrm{S}_{\mathrm{C}}$ phase. Nevertheless, we imagine that the polymer chains are more or less confined between the layers of the $S_{C}$ phase, but some investigations, in particular by neutron diffraction measurement, are necessary to confirm this organization [43].

role played by the tilt of the mesogens on the position and the conformation of the polymer backbone within the layers of the smectic $\mathrm{C}$ structure.

Finally. the problem of the backbone conformation in the nematic or smectic phases has been addressed since ten years for side-end fixed polymers. For these last ones, theoretical modelizations have been built to account for their different conformations, in particular by Warner et al. [41]. In order to test a model, many experimental results are now available on the polymer behaviour for the side-on fixed LCPs $[1-8,32,33]$. It could be very interesting to describe the inversion of conformation associated with the $\mathrm{N}-\mathrm{S}_{\mathrm{C}}$ phase transition in terms of interactions from a theoretical approach closely connected to the Warner et al. model [41].

\section{References}

[1] Hardouin F., Mery S., Achard M.F.. Noirez L. and Keller P., J. Phys. II France 1 (1991) 511 and Erratum, J. Phys. II France 1 (1991) 871.

[2] Méry S., PhD Thesis 1990 Bordeaux, France (in french).

[3] Hardouin F., Leroux N., Mery S. and Noirez L., J. Phys. II France 2 (1992) 271.

[4] Leroux N., Keller P., Achard M.F., Noirez L. and Hardouin F., J. Phys. II France 3 (1993) 1289 .

[5] Leroux N., PhD Thesis 1992 Bordeaux, France (in french).

[6] Leroux N., Mauzac M., Noirez L. and Hardouin F., Lıq. Cryst. 16 (1994) 42.

[7] Lecommandoux S., Noirez L., Richard H., Achard M.F., Strazielle C. and Hardouin F., J. Phys. II France 6 (1996) 225.

[8] Hardouin F., Leroux N., Noirez L., Keller P., Mauzac M. and Achard M.F., Mol. Cryst. Liq. Cryst. 254 (1994) 267.

[9] Noirez L., Davidson P., Schwartz W. and Pépy G., Liq. Cryst. 16 (1994) 1081.

[10] Noirez L., Keller P. and Cotton J.P., Lıq. Cryst. 18 (1995) 129 and references therein. 
[11] Lecommandoux S., Noirez L., Mauzac M. and Hardouin F., J. Phys. II France 4 (1994) 2249.

[12] Noirez L., Cotton J.P., Hardouin F., Keller P., Moussa F., Pepy G. and Strazielle C., Macromol. 21 (1988) 2891.

[13] Davidson P., Keller P. and Levelut A.M., J. Phys. France 46 (1985) 939.

[14] Davidson P., Levelut A.M., Achard M.F. and Hardouin F., Liq. Cryst. 4 (1989) 561; Davidson P. and Levelut A.M., Liq. Cryst. 11 (1992) 469.

[15] see for example: Finkelmann H. and Rehage G., Advances in Polymer Science, 60-61 (Springer Verlag, Berlin. 1984) p. 99; Shibaev V.P., Platé N.A., Advances in Polymer Science, 60-61 (Springer Verlag, Berlin,1984) p. 175; Mc Ardle, Side chain Liquid Crystal Polymers (Blackie, Chapman and Hall, New York, 1989).

[16] Hessel F. and Finkelmann H., Polym. Bull. 14 (1985) 375.

[17] Hessel F., Herr R. and Finkelmann H., Makromol. Chem. 188 (1987) 1597.

[18] Hessel F. and Finkelmann H., Makromol. Chem. 189 (1988) 2275.

[19] Qi-Feng Zhou, Hui-Min Li and Xin-De Feng, Macromol. 20 (1987) 233.

[20] Qi-Feng Zhou, Hui-Min Li and Xin-De Feng, Mol. Cryst. Lıq. Cryst. 155 (1988) 73.

[21] Keller P., Hardouin F., Mauzac M. and Achard M.F., Mol. Cryst. Liq. Cryst. 155 (1988) 171.

[22] Gray G.W. Hill J.S. and Lacey D., Angew. Chem. Int. Engl. Adv. Mater. 28 (1989) 1120.

[23] Hardouin F., Méry S., Achard M.F., Mauzac M. and Davidson P., Liq. Cryst. 8 (1990) 565.

[24] Lewthwaite R.W., Gray G.W. and Toyne K.J.. J. Mater. Chem. 2 (1992) 119.

[25] Percec V. and Tomazos D., J. Mater. Chem. 3 (1993) 643.

[26] Pugh C. and Schrock R., Macromol. 25 (1992) 6593.

[27] Leube H.F. and Finkelmann H., Makromol. Chem. 191 (1990) 2707.

[28] Leube H.F. and Finkelmann H., Makromol. Chem. 192 (1991) 1314.

[29] Achard M.F., Lecommandoux S. and Hardouin F., Liq. Cryst. 19 (1995) 581.

[30] Pugh C., Liu H.. Arehart S.V. and Narayanan R., Macromol. Symp. 98 (1995) 293.

[31] Takenaka S. and Yamasaki K., Mol. Cryst. Liq. Cryst. 258 (1995) 51.

[32] Lecommandoux S., Noirez L., Achard M.F. and Hardouin F., submitted in J. Phys. II. France

[33] Lecommandoux S., Achard M.F., Richard H. and Hardouin F., submitted in Liq. Cryst.

[34] a) Cotton J.P., Decker D., Benoît H.. Farnoux B., Higgins J., Jannink G., Ober R., Picot C. and des Cloizeaux J.. Macromol. 7 (1974) 863; b) Cotton J.P., Neutron, 'X-ray and Light Scattering", P. Linder and Th. Zemb, Eds. (Elsevier, 1991).

[35] Boué F., Nierlich M. and Leibler L., Polymer 23 (1982) 29.

[36] Lapp A., Picot C. and Benoît H., Macromol. 18 (1985) 2437.

[37] Hardouin F., Méry S., Achard M.F.. Mauzac M. and Davidson P., Liq. Cryst. 8 (1990) 565.

[38] Cherodian A.S., Hughes N.J., Richardson R.M., Lee M.S.K. and Gray G.W., Lzq. Cryst. 14 (1993) 1667.

[39] Diele S., Roth K. and Demus D., Cryst. Res. Technol. 21 (1986) 97.

[40] see for example: Noël C., Side chain liquid crystal polymers, C.B. Mc Ardle, Ed. (Blackie, 1989) chap. 6 and references therein.

[41] Wang X.J. and Warner M., J. Phys. A: Math. Gen. 20 (1987) 713; Renz W. and Warner M., Proc. R. Soc. Lond. A 417 (1988) 213.

[42] Noirez L., Keller P., Davidson P., Hardouin F. and Cotton J.P., J. Phys. France 49 (1988) 1993.

[43] Noìrez L., Mol. Cryst. Lıq. Cryst. 261 (1995) 525. 